\title{
Central pulmonary arteries in idiopathic pulmonary fibrosis: size really matters
}

\author{
Laura C. Price ${ }^{1}$, Anand Devaraj ${ }^{2}$ and S. John Wort ${ }^{1}$ \\ Affiliations: ${ }^{1}$ Pulmonary Hypertension Service, Royal Brompton Hospital, London, UK. ${ }^{2}$ Dept of Radiology, \\ Royal Brompton Hospital, London, UK.
}

Correspondence: S. John Wort, Pulmonary Hypertension Service, Royal Brompton Hospital, Sydney Street, London SW3 6NP, UK. E-mail: s.wortवimperial.ac.uk

。 $@$ ERSpublications

Despite the uncertainties of why, when it comes to PH risk in IPF, pulmonary artery size clearly matters http://ow.ly/YlKVy

Idiopathic pulmonary fibrosis (IPF) is the most common of the idiopathic interstitial pneumonias and is often associated with pulmonary hypertension $(\mathrm{PH})$. The presence of $\mathrm{PH}$ has major implications for a patient with IPF in terms of exercise capacity and mortality $[1,2]$. Early and accurate detection of PH is therefore important for prognostication, timing of referral for transplantation and possible entry into clinical trials. The gold standard investigation for confirming $\mathrm{PH}$ in this population, as in any patient, remains right heart catheterisation (RHC). However, performing RHC in patients with IPF is not without risk in what is an older population, often with serious comorbidities. Informed referral for RHC, based on clinical signs and noninvasive tests suggestive of $\mathrm{PH}$, is therefore desirable. Unfortunately, clinical signs of $\mathrm{PH}$ are often unreliable in patients with any chronic respiratory disease, let alone IPF, and standard tests such as echocardiography can be surprisingly inaccurate [3, 4]. There remains the need, therefore, to further interrogate noninvasive methods of detection of $\mathrm{PH}$ in patients with chronic respiratory disease, including IPF. The concept that the size of the pulmonary artery (PA) derived from a computed tomography (CT) scan might predict the presence of $\mathrm{PH}$ and even determine outcome in patients with IPF, as suggested by SHIN et al. [5] in this issue of the European Respiratory Journal, is therefore very appealing and potentially widely applicable.

The association of an increase in main PA diameter (dPA) with the presence of PH measured invasively has been known for a while and makes intuitive sense [6-8]. In 1999, PADLEY et al. suggested that the ratio of the main PA (at the PA bifurcation) to adjacent ascending aorta (rPA) as measured by CT in a heterogeneous group of patients with cardiorespiratory disease was a better predictor of the presence of PH than dPA, partly because dPA appeared to depend on other factors, such as body surface area. The "rPA $>1$ sign" predicted the presence of $\mathrm{PH}$ with sensitivity, specificity, and positive and negative predictive values of $70 \%, 92 \%, 96 \%$ and $52 \%$, respectively, in the reported cohort, although it must be stressed that the cut-off for $\mathrm{PH}$ was $20 \mathrm{mmHg}$ in this study and not the current accepted value of $25 \mathrm{mmHg}$ [9]. Despite this, the rPA $>1$ sign has remained a useful clinical tool.

However, a question mark still remains as to whether dPA or rPA are as reliable in patients with chronic lung disease at determining the presence of $\mathrm{PH}$ [10]. Certainly, in patients with advanced chronic obstructive pulmonary disease (COPD), it appears that $\mathrm{dPA}$, and in particular, rPA, correlates well with mean PA pressure (mPAP) $[11,12]$. However, in patients with lung fibrosis, the relationship between $\mathrm{dPA}$ and $\mathrm{PH}$ appears less robust [13, 14]. For instance, DEVARAj et al. [13] demonstrated a poor correlation of baseline mPAP and pulmonary vascular resistance index with $\mathrm{dPA}$ in patients with a mixed group of interstitial lung disease (ILD), compared to those without ILD, although the use of the rPA in the ILD group significantly improved the correlation. Importantly, patients with fibrosis and no $\mathrm{PH}$ or very low levels of $\mathrm{PH}$ still had evidence of increased dPA. The authors concluded that $\mathrm{dPA}$ alone is an unreliable sign of $\mathrm{PH}$ in patients with ILD and that rPA was better. More recently, McCALL et al. [15] have only partially corroborated this

Received: Feb 042016 | Accepted: Feb 052016

Conflict of interest: Disclosures can be found alongside the online version of this article at erj.ersjournals.com

Copyright (CERS 2016 
finding, at least in patients with scleroderma and PH. In their study, dPA ( $>30 \mathrm{~mm}$ ) was as good as $\mathrm{rPA}$ at predicting the presence of $\mathrm{PH}$ and only when the level of lung fibrosis was severe (defined as forced vital capacity $<70 \%$ predicted), was the correlation between mPAP and $\mathrm{dPA}$ attenuated.

SHIN et al. [5] retrospectively evaluated high-resolution (HR)CTs in 98 patients with IPF over a 5-year period for $\mathrm{dPA}$ and $\mathrm{rPA}$, as well as the presence of aortic aneurysm; they correlated the first two of these parameters with the outcome measures, transplant or death. There was excellent intraclass correlation amongst three independent readers for the CT-derived parameters. The authors measured baseline severity of IPF in terms of lung function and GAP (gender, age, physiology) scores [16], although a fibrosis severity scoring by HRCT was not performed. Contemporaneous RHC data were available in only one-third of patients and in these, there was a weak but positive correlation of mPAP with rPA, confirming what we already know, that at least in IPF, these parameters are not that reliable. The main and novel finding of this study was that patients with a $\mathrm{dPA}>32.3 \mathrm{~mm}$ or an $\mathrm{rPA}>1$ had worse outcome. Cox proportional hazard analysis confirmed that $\mathrm{rPA}>1$ was a strong independent predictor of worse outcome and, interestingly, performed better than the GAP score. Certainly, those patients with an $\mathrm{rPA}>1$ had more severe abnormalities of lung function and a worse GAP score compared to the group with $\mathrm{rPA}<1$. This suggests that $\mathrm{rPA}$ in this group may be reflecting the severity of disease, which in turn includes the extent of both fibrosis and $\mathrm{PH}$. Both these factors are then driving the poorer outcome. Of note, $6 \%$ of the cohort had thoracic aortic aneurysmal enlargement, which although higher than in the general population in the USA (4.6\%), is unlikely to have affected the study results.

Interestingly, the same authors have already demonstrated that an $\mathrm{rPA}>1$ is related to poorer outcome in patients with severe COPD [12]. In these patients, in a Cox proportional hazards model, only rPA $>1$ was independently related to outcome, and not forced expiratory volume in $1 \mathrm{~s}$, body mass index or age. $\mathrm{PH}$ itself was not. It led the authors to suggest that factors other than $\mathrm{PH}$ are important in contributing to the rPA effect on outcome. Interestingly, this may include the recently described relationship of rPA with acute exacerbations in both COPD and ILD [17, 18]. Other possibilities include contribution of the underlying lung disease, as described above, or other comorbidities associated with $\mathrm{PH}$, such as obstructive sleep apnoea and venous thromboembolism.

Worthy of consideration is the change in measured parameters such as APA and rPA over time, and the relationship of change with outcome. A subset of patients with IPF, as previously identified by NATHAN et al. [19], develop rapidly progressive $\mathrm{PH}$ and have a particularly bad prognosis. Perhaps change in dPA or rPA may help to identify these "rapid progressors"? A recent magnetic resonance study by BOERRIGTER et al. [20] examined the relationship between $\mathrm{dPA}$, intraluminal PA pressure and duration of the disease in patients with pulmonary arterial hypertension (PAH) (i.e. without lung fibrosis). The authors demonstrated an inverse correlation of $\mathrm{dPA}$ with age, which was thought to probably reflect age-related fibrosis of the PA wall, making it less prone to dilatation over time. This is a novel finding in the PAH literature that has not been examined in patients with ILD, and may contribute to the complex relationship of dPA and rPA with outcome. Further studies of serial change in these parameters are clearly warranted.

Finally, what about comparing CT-derived measurements with other noninvasive tests such as echocardiography, or combining different noninvasive tests? DeVAraj et al. [21] found that echocardiography-derived systolic PA pressure (sPAP) and rPA correlated equally as well with invasively derived $\mathrm{MPAP}$ in a heterogenous population, including some patients with IPF. The same authors showed that combining rPA with sPAP correlated better with mPAP than either alone. A similar result was reported by CONDLIFFE et al. [22] in patients with systemic sclerosis-associated PAH. In addition, in a COPD population, IYER et al. [11] found that echocardiography was inferior to rPA at determining the presence of $\mathrm{PH}$, although the predictive ability of both combined was not tested. Again, further studies are needed, this time on combining other noninvasive tests to $\mathrm{dPA}$ and $\mathrm{rPA}$ in patients with IPF as predictors of the presence of $\mathrm{PH}$ and outcome.

Therefore, despite the uncertainties of why, size clearly matters. Patients with IPF, as well as COPD, who have an $\mathrm{rPA}>1$ measured on $\mathrm{CT}$ are at greater risk of dying. These patients should be identified as candidates for earlier referral for transplantation, optimisation of therapy for their underlying condition and potential inclusion in well-designed clinical trials to investigate treatment of the underlying PH.

\section{References}

1 Corte TJ, Wort SJ, Gatzoulis MA, et al. Pulmonary vascular resistance predicts early mortality in patients with diffuse fibrotic lung disease and suspected pulmonary hypertension. Thorax 2009; 64: 883-888.

2 Boutou AK, Pitsiou GG, Trigonis I, et al. Exercise capacity in idiopathic pulmonary fibrosis: the effect of pulmonary hypertension. Respirology 2011; 16: 451-458.

3 Arcasoy SM, Christie JD, Ferrari VA, et al. Echocardiographic assessment of pulmonary hypertension in patients with advanced lung disease. Am J Respir Crit Care Med 2003; 167: 735-740. 
Nathan SD, Shlobin OA, Barnett SD, et al. Right ventricular systolic pressure by echocardiography as a predictor of pulmonary hypertension in idiopathic pulmonary fibrosis. Respir Med 2008; 102: 1305-1310.

5 Shin S, King CS, Puri N, et al. Pulmonary artery size as a predictor of outcomes in idiopathic pulmonary fibrosis. Eur Respir J 2016; 47: 1445-1451.

6 Grubstein A, Benjaminov O, Dayan DB, et al. Computed tomography angiography in pulmonary hypertension. Isr Med Assoc J 2008; 10: 117-120.

7 Kuriyama K, Gamsu G, Stern RG, et al. CT-determined pulmonary artery diameters in predicting pulmonary hypertension. Invest Radiol 1984; 19: 16-22.

8 Schmidt HC, Kauczor HU, Schild HH, et al. Pulmonary hypertension in patients with chronic pulmonary thromboembolism: chest radiograph and CT evaluation before and after surgery. Eur Radiol 1996; 6: 817-825.

9 Ng CS, Wells AU, Padley SP. A CT sign of chronic pulmonary arterial hypertension: the ratio of main pulmonary artery to aortic diameter. J Thorac Imaging 1999; 14: 270-278.

10 Moore NR, Scott JP, Flower CD, et al. The relationship between pulmonary artery pressure and pulmonary artery diameter in pulmonary hypertension. Clin Radiol 1988; 39: 486-489.

11 Iyer AS, Wells JM, Vishin S, et al. CT scan-measured pulmonary artery to aorta ratio and echocardiography for detecting pulmonary hypertension in severe COPD. Chest 2014; 145: 824-832.

12 Shin S, King CS, Brown AW, et al. Pulmonary artery size as a predictor of pulmonary hypertension and outcomes in patients with chronic obstructive pulmonary disease. Respir Med 2014; 108: 1626-1632.

13 Devaraj A, Wells AU, Meister MG, et al. The effect of diffuse pulmonary fibrosis on the reliability of CT signs of pulmonary hypertension. Radiology 2008; 249: 1042-1049.

14 Zisman DA, Karlamangla AS, Ross DJ, et al. High-resolution chest CT findings do not predict the presence of pulmonary hypertension in advanced idiopathic pulmonary fibrosis. Chest 2007; 132: 773-779.

15 McCall RK, Ravenel JG, Nietert PJ, et al. Relationship of main pulmonary artery diameter to pulmonary arterial pressure in scleroderma patients with and without interstitial fibrosis. J Comput Assist Tomogr 2014; 38: 163-168.

16 Ley B, Ryerson CJ, Vittinghoff E, et al. A multidimensional index and staging system for idiopathic pulmonary fibrosis. Ann Intern Med 2012; 156: 684-691.

17 Wells JM, Washko GR, Han MK, et al. Pulmonary arterial enlargement and acute exacerbations of COPD. N Engl J Med 2012; 367: 913-921.

18 Judge EP, Fabre A, Adamali HI, et al. Acute exacerbations and pulmonary hypertension in advanced idiopathic pulmonary fibrosis. Eur Respir J 2012; 40: 93-100.

19 Nathan SD, Shlobin OA, Ahmad S, et al. Serial development of pulmonary hypertension in patients with idiopathic pulmonary fibrosis. Respiration 2008; 76: 288-294.

20 Boerrigter B, Mauritz GJ, Marcus JT, et al. Progressive dilatation of the main pulmonary artery is a characteristic of pulmonary arterial hypertension and is not related to changes in pressure. Chest 2010; 138: 1395-1401.

21 Devaraj A, Wells AU, Meister MG, et al. Detection of pulmonary hypertension with multidetector CT and echocardiography alone and in combination. Radiology 2010; 254: 609-616.

22 Condliffe R, Radon M, Hurdman J, et al. CT pulmonary angiography combined with echocardiography in suspected systemic sclerosis-associated pulmonary arterial hypertension. Rheumatology 2011; 50: 1480-1486. 